\title{
Epidemiology incidence and geographical distribution of leptospirosis using GIS and its incidence prediction in Iran in 2021
}

\author{
Ghobad Moradi ${ }^{1}$, Hossein Masoumi Asl ${ }^{2}$, Nasrin Bahmani ${ }^{3}$, Ahmad Vahabi $^{3}$, Samira Shirzadi ${ }^{4}$, Zahra Zare ${ }^{5}$, Elham \\ Goodarzi $^{6}$, Hasan Naemi ${ }^{7}$, Zaher Khazaei ${ }^{8 *} \mathbb{D}$, Asrin Karimi ${ }^{1}$
}

Received: 14 Feb 2020

Published: 25 Aug 2021

\section{Abstract}

Background: Leptospirosis is known as a public health problem in developing and developed countries. The aim of this study was to investigate the incidence and geographical distribution of leptospirosis using the Geographic Information System (GIS) and to predict its incidence in Iran in 2021.

Methods: This was a descriptive analytical study. Information on leptospirosis was obtained from the Center for Communicable Diseases Control during 2009-2015. In the next step, The ArcGIS 9.3 was used to prepare geographic maps of the disease incidence and frequency. Therefore, using the Raster Calculator tool, the disease prediction map was drawn.

Results: The results showed that the highest incidence of leptospirosis during 2009-2015 was observed in Gilan, Mazandaran, and Golestan provinces, respectively. The incidence of the disease had an increasing trend from 2013 to 2015. Based on the results of the modeling in Iran, the provinces of Gilan, Mazandaran, and Golestan, with $72.18 \%, 8.54 \%$, and $4.95 \%$ of their area, respectively, have the largest areas at a high-risk for leptospirosis in the coming years.

Conclusion: The prevalence of leptospirosis is affected by geographical and climatic conditions of every region; thus, the incidence of the disease is higher in the provinces located at the Caspian coastal side and in some regions in Semnan province. Hence, if health authorities pay more attention to developing health plans to prevent the disease, the risk of disease in these areas will be reduced in the future.

Keywords: Incidence, Leptospirosis, GIS, Iran

Conflicts of Interest: None declared

Funding: Kurdistan University of Medical Sciences

\section{*This work has been published under CC BY-NC-SA 1.0 license. \\ Copyright $\odot$ Iran University of Medical Sciences}

Cite this article as: Moradi G, Masoumi Asl H, Bahmani N, Vahabi A, Shirzadi S, Zare Z, Goodarzi E, Naemi H, Khazaei Z , Karimi A. Epidemiology incidence and geographical distribution of leptospirosis using GIS and its incidence prediction in Iran in 2021 . Med J Islam Repub Iran 2021 (25 Aug);35:109. https://doi.org/10.47176/mjiri.35.109

\section{Introduction}

Leptospirosis is one of the most widespread zoonotic diseases common to humans and animals that has been recognized as one of the largest zoonosis in the world (1). According to a report by the World Health Organization,

Corresponding author: Zaher Khazaei, Zaherkhazaei@yahoo.com

${ }^{1 .}$ Social Determinants of Health Research Center, Research Institute for Health Development, Kurdistan University of Medical Sciences, Sanandaj, Iran

2. Center for Communicable Diseases Control, Ministry of Health and Medical Education, Tehran, Iran

3. Zoonoses Research Center, Research Institute for Health Development, Kurdistan University of Medical Sciences, Sanandaj, Iran

4. Payame Noor University, Tehran, Iran

5. Zoonosis Research Center, Tehran University of Medical Sciences, Tehran, Iran

${ }^{6}$ Social Determinants of Health Research Center, Lorestan University of Medical Sciences, Khorramabad, Iran

7. Cellular and Molecular Research Center, Sabzevar University of Medical Sciences, Sabzevar, Iran

8. Department of Public Health, School of Medicine, Dezful University of Medical Sciences, Dezful, Iran the number of human cases of leptospirosis is not known precisely because of a lack of awareness of the disease and problems associated with diagnostic tests (2). In recent years, the incidence of leptospirosis has increased in

$\uparrow$ What is "already known" in this topic:

Mild and wet weather conditions in Northern provinces of Iran have put this area at more risk for leptospirosis.

\section{$\rightarrow$ What this article adds:}

It has been predicted that the incidence of leptospirosis disease is higher in the provinces located at the Caspian coastal side and in some regions in Semnan province. Therefore, authorities should pay more attention to develop programs to identify and prevent the spread of the disease. 
many parts of the world and it has become a recurrent disease (3).

Leptospirosis is observed in people who are in contact with water or wastewater, such as rice workers, fishermen, sewage workers, and miners. Among the mentioned occupations, rice field workers who are in contact with contaminated soil and water are the largest group affected by leptospirosis (4).

Risk factors for this disease include living in rural and tropical areas, exposure to water contaminated with the disease factor, living on the side of sewage channels, and working in health facilities (5). Favorable weather conditions, soil $\mathrm{pH}$, the rate of rain fall and humidity, presence of stagnant or swampy waters, and increasing the population of rodents in a region can increase the incidence of the disease. Therefore, it is more prevalent and endemic in tropical, subtropical, and temperate regions, especially in hot and humid regions (6). Therefore, the disease is more prevalent in the northern region of Iran, especially Gilan and Mazandaran provinces (7).

Understanding the effective risk factors can help to recognize the transmission cycle as well as the ways of disease spread in areas with a high incidence of the disease (8); therefore, assessing the geographical distribution and trends of the disease in different regions can help health planners to focus more on executive programs on highrisk areas. In addition, determining the geographical distribution of the disease can provide a useful tool for evaluating the effectiveness and success of control programs (9). Therefore, like other epidemics, understanding the geographical pattern of the incidence and prevalence of leptospirosis can be crucial for implementing interventions and managing and controlling the disease $(10,11)$.

The Geographic Information System (GIS) has been applied in 2 areas of health, including epidemiology and health care $(12,13)$. The use of the GIS is of great importance for the management of health systems and infrastructures (14). The GIS is a practical software that can provide a geographical distribution pattern for diseases such as tuberculosis, malaria, Malta fever, and many other diseases to investigate the influencing factors and causes and represent the spatial distribution of the disease both quantitatively and quantitatively. The results can be very helpful in making health decisions to prevent and control diseases (15-18).

Therefore, since public health issues and disease spread are directly related to the geography of the region and always have a spatial dimension, the GIS can play a significant role in managing and planning public health programs and studying disease spread $(18,19)$. According to some experts, disease mapping is the first step in designing advanced disease alarm and management systems (19); hence, the aim of the present study was to investigate the incidence and geographical distribution of leptospirosis using the GIS and prediction of its incidence in Iran in 2021.

\section{Methods}

This research was conducted as a descriptive analytical study and its results can be practically utilized. The re- search setting included spatial and climatic information and the spread of leptospirosis in Iran. At first, the data on leptospirosis from 2009 to 2015 were collected from the Center for Communicable Diseases Control. The data on leptospirosis was categorized in tables in terms of frequency and incidence for each year, and the incidence rate was calculated for cases per 100,000 population in the country. In the next stage, the GIS software was used to prepare geographical maps and assess the incidence and frequency of the disease.

To prepare the spatial database for the disease, the research team used the vector map of the country prepared in 2017 by the National Mapping Organization. Also, to link descriptive information rellated to the disease with the spatial data, a GIS mapping was prepared and its accuracy was assessed using Google earth software. After preparing the geographic database of the disease, descriptive data, such as incidence and frequency of the disease, were added to the GIS descriptive table using Excel software. In the next stage, using the GIS software and symbology functions, a spatial analysis was conducted to prepare a map of the distribution of disease incidence and frequency from 2009 to 2015 . Using the data on each province, the map of the incidence and frequency of the disease was prepared for the whole country. Finally, to draw a prediction map for the future status of the disease, it was assumed that the regions with the highest incidence, frequency, and recurrence of the disease in a statistical period have the highest probabillity of disease occurrence. Therefore, the Raster calculator tool was used to multiply a phase map of the disease within a specific period by a disease recurrence map, and finally a disease prediction map was drawn for the future time (20). The most likely areas at risk of the disease incidence are shown with red in the map.

With the information of each province available, the incidence and frequency of the disease was developed for the whole country. To plot the map of interpolation, the inverse distance interpolation method was used (21).

\section{High-risk Points Analysis}

The Getis-Ord-Gi* statistic was used for an appropriate spatial distribution of hot and cold spots. A disease is recognized as a hot spot when its figures and those of its surrounding conditions are fairly high. When the Getis-OrdGi* statistic is calculated to be 1,2 , and 3, the CI is estimated at $99 \%, 95 \%$, and $90 \%$, respectively (22).

As the incidence data are obtained based on the findings of routine health care system, the difference in incidence that was observed in different provinces can be largely dependent on the sensitivity of the health care system to record and report cases in these provinces.

\section{Results}

The results showed that the total number of reported cases of leptospirosis during 2009-2015 was 2288 cases, and its frequency was much higher in men than in women $(67.9 \%$ vs $32.1 \%)$. Of all, $67.6 \%$ of the patients were living in rural areas. The results showed that the outcome was treatment in $98.5 \%$ of cases. On the other hand, the 


\begin{tabular}{llc}
\multicolumn{2}{l}{ Table 1. Demographic data of patients with Leptospirosis in Iran from 2009 to 2015} & \\
\hline Variable & & Frequency (\%) \\
\hline Gender & Female & $735(32.1)$ \\
& Male & $1553(67.9)$ \\
Location of residence & Rural area & $1547(67.6)$ \\
& Urban area & $740(32.4)$ \\
Disease outcome & Treatment & $2253(98.5)$ \\
& Death & $34(1.5)$ \\
History of travel & Yes & $152(6.6)$ \\
& No & $2127(93)$ \\
& Unknown & $9(0.4)$ \\
& Pulmonary complications & $38(1.7)$ \\
& Renal failure & $30(1.3)$ \\
& Renal failure and pulmonary complications & $2(0.1)$ \\
Disease complication & $651(28.5)$ \\
& Hepatitis & $4(0.2)$ \\
& Hepatitis and pulmonary complications & $5(0.2)$ \\
& Renal failure, hepatitis, and pulmonary complications & $1544(67.5)$ \\
\hline
\end{tabular}

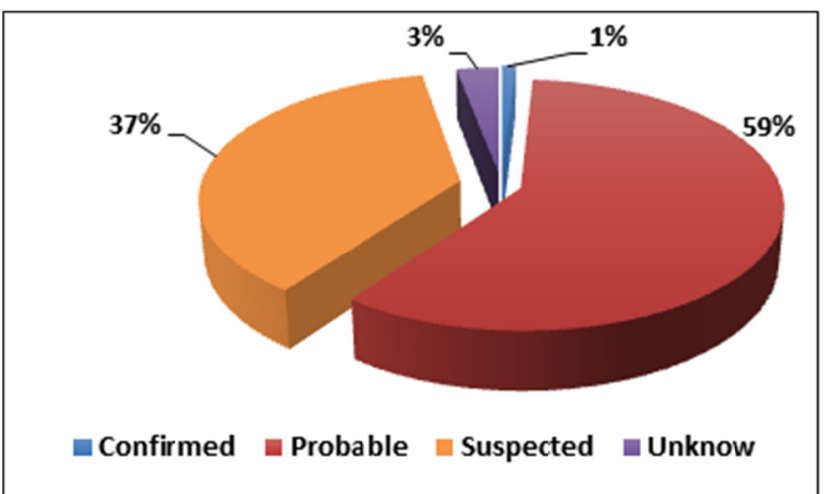

Fig. 1. Frequency of leptospirosis in patients based on the results of tests

most reported complication was hepatitis (28.5\%) (Table 1).

Of the 2288 cases reported during these years, 59\% were probable cases and only about $1 \%$ were diagnosed as confirmed cases (Fig. 1).

The results of the study showed that the highest inci-

Table 2. Leptospirosis incidence rate per 100,000 population in Iran during 2009-2015

\begin{tabular}{|c|c|c|c|c|c|c|c|}
\hline Province & 2009 & 2010 & 2011 & 2012 & 2013 & 2014 & 2015 \\
\hline Azarbaijan Sharghi & 0.00 & 0.00 & 0.00 & 0.00 & 0.00 & 0.00 & 0.00 \\
\hline Azarbaijan Gharbi & 0.00 & 0.00 & 0.00 & 0.00 & 0.00 & 0.00 & 0.00 \\
\hline Ardebil & 0.00 & 0.00 & 0.00 & 0.00 & 0.00 & 0.00 & 0.00 \\
\hline Esfahan & 0.00 & 0.00 & 0.00 & 0.00 & 0.00 & 0.00 & 0.00 \\
\hline Alborz & 0.00 & 0.00 & 0.00 & 0.08 & 0.08 & 0.04 & 0.00 \\
\hline Eilam & 0.00 & 0.00 & 0.00 & 0.00 & 0.00 & 0.00 & 0.00 \\
\hline Boshehr & 0.00 & 0.00 & 0.00 & 0.00 & 0.00 & 0.00 & 0.00 \\
\hline Tehran & 0.00 & 0.02 & 0.03 & 0.00 & 0.00 & 0.00 & 0.02 \\
\hline Cheharmahal Bakhtiari & 0.00 & 0.00 & 0.00 & 0.00 & 0.00 & 0.00 & 0.00 \\
\hline Khorasan Jonobi & 0.00 & 0.00 & 0.00 & 0.00 & 0.00 & 0.00 & 0.00 \\
\hline Khorasan Razavi & 0.00 & 0.00 & 0.00 & 0.00 & 0.00 & 0.00 & 0.02 \\
\hline Khorasan Shomali & 0.00 & 0.00 & 0.00 & 0.00 & 0.00 & 0.00 & 0.22 \\
\hline Khozestan & 0.00 & 0.00 & 0.00 & 0.00 & 0.00 & 0.00 & 0.04 \\
\hline Zanjan & 0.00 & 0.00 & 0.00 & 0.00 & 0.00 & 0.00 & 0.00 \\
\hline Semnan & 0.00 & 0.00 & 0.00 & 0.00 & 0.00 & 0.00 & 0.15 \\
\hline Sistan o Baluchestan & 0.00 & 0.00 & 0.00 & 0.00 & 0.00 & 0.00 & 0.00 \\
\hline Fars & 0.00 & 0.07 & 0.02 & 0.00 & 0.00 & 0.00 & 0.00 \\
\hline Ghazvin & 0.00 & 0.00 & 0.00 & 0.00 & 0.00 & 0.00 & 0.00 \\
\hline Ghom & 0.00 & 0.00 & 0.00 & 0.00 & 0.00 & 0.00 & 0.00 \\
\hline Kurdistan & 0.00 & 0.00 & 0.00 & 0.00 & 0.00 & 0.07 & 0.07 \\
\hline Kerman & 0.00 & 0.00 & 0.00 & 0.00 & 0.00 & 0.00 & 0.00 \\
\hline Kermanshah & 0.00 & 0.00 & 0.00 & 0.00 & 0.00 & 0.00 & 0.00 \\
\hline Kohgiloyeh o Boirahmad & 0.00 & 0.00 & 0.00 & 0.15 & 0.15 & 0.00 & 0.00 \\
\hline Golestan & 2.45 & 3.10 & 1.07 & 0.66 & 0.65 & 0.75 & 0.84 \\
\hline Guilan & 9.98 & 17.95 & 6.89 & 3.73 & 3.70 & 8.51 & 12.86 \\
\hline Lorestan & 0.00 & 0.06 & 0.00 & 0.00 & 0.00 & 0.00 & 0.00 \\
\hline Mazandaran & 0.86 & 5.29 & 0.88 & 0.87 & 0.86 & 1.27 & 1.92 \\
\hline Markazi & 0.00 & 0.07 & 0.00 & 0.00 & 0.00 & 0.07 & 0.14 \\
\hline Hormozgan & 0.00 & 0.00 & 0.00 & 0.12 & 0.12 & 0.00 & 0.00 \\
\hline Hamadan & 0.00 & 0.00 & 0.00 & 0.00 & 0.00 & 0.00 & 0.00 \\
\hline Yaze & 0.00 & 0.00 & 0.00 & 0.00 & 0.00 & 0.00 & 0.00 \\
\hline Iran & 0.43 & 0.90 & 0.30 & 0.18 & 0.18 & 0.35 & 0.53 \\
\hline
\end{tabular}


dence of leptospirosis during 2009-2015 was observed in Gilan, Mazandaran, and Golestan provinces, respectively (Table 2).

The results of the study showed that the highest incidence of leptospirosis in Iran was observed in 2010, with a decreasing trend from 2010 to 2013, and a recurrence and an increasing trend from 2013 to 2015 (Fig. 2).

Figure 3 presents GIS maps of the incidence of leptospirosis in different provinces during 2009-2015 (Fig. 3).

According to the latest information on the incidence of the disease (incidence in 2015), Gilan, Mazandaran, and Golestan provinces had the highest incidence in 2015.

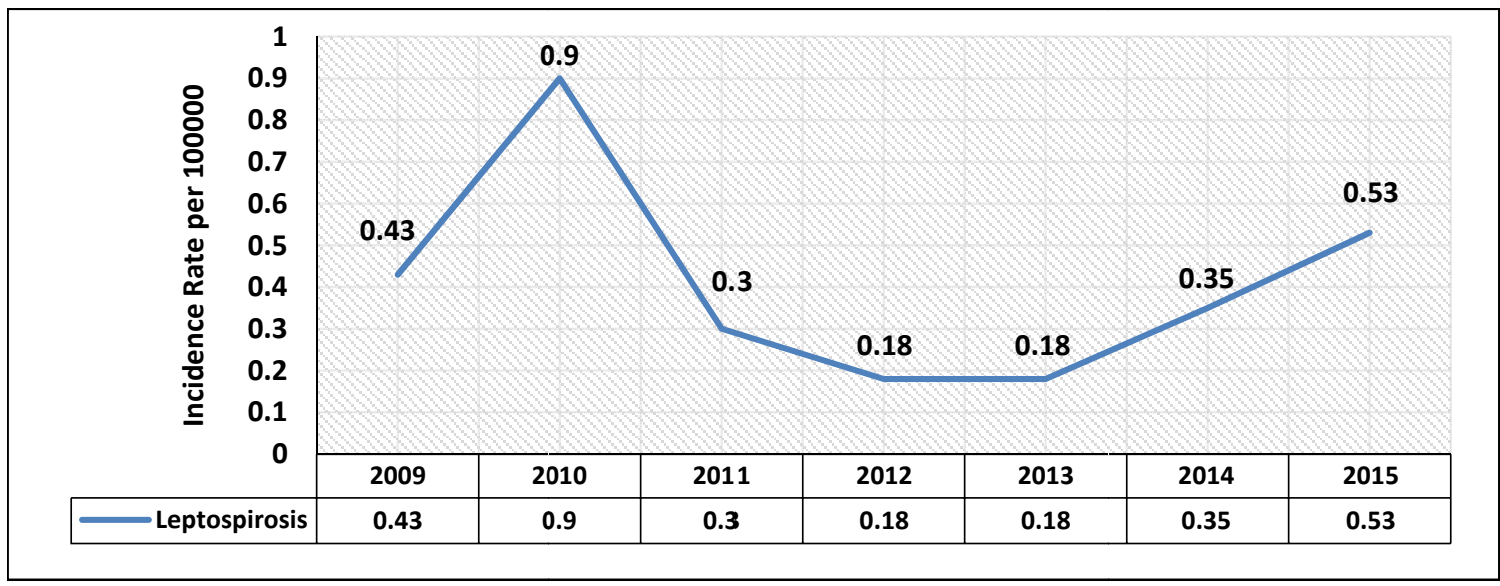

Fig. 2. Trend of leptospirosis disease in Iran during 2009-2015
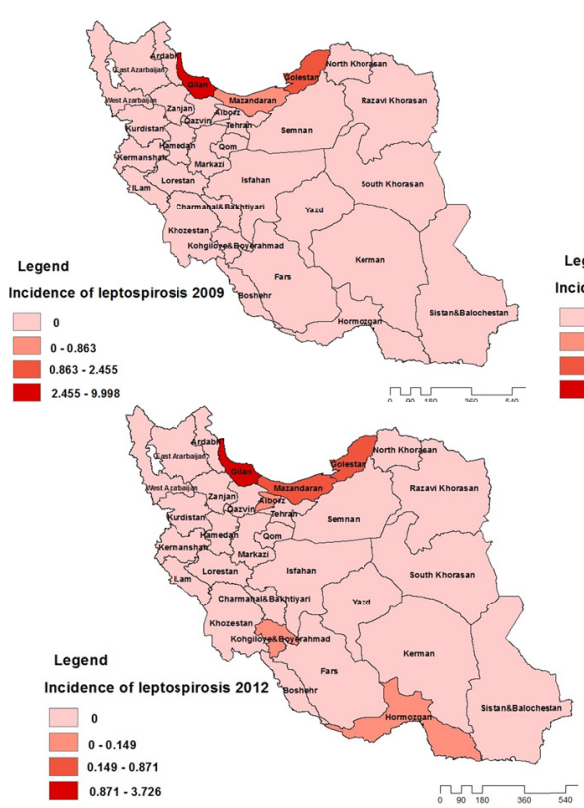
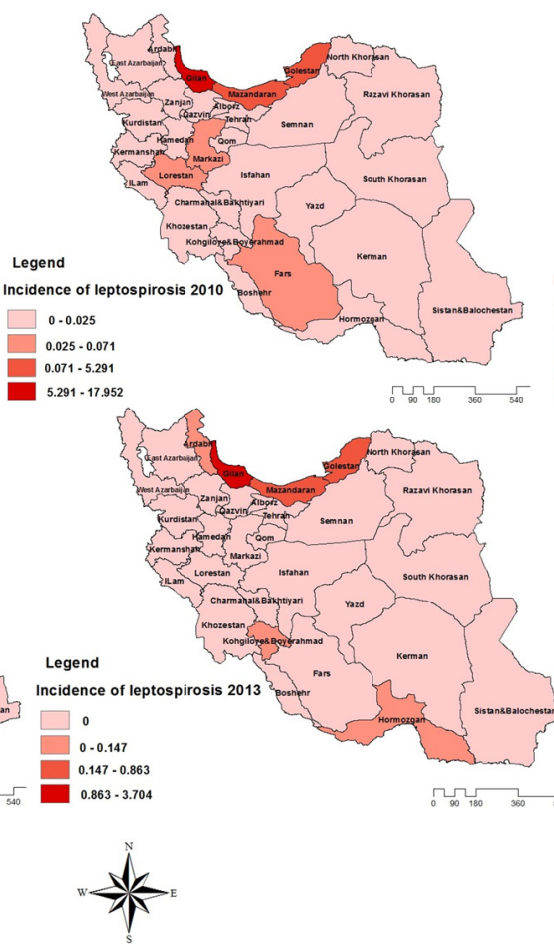
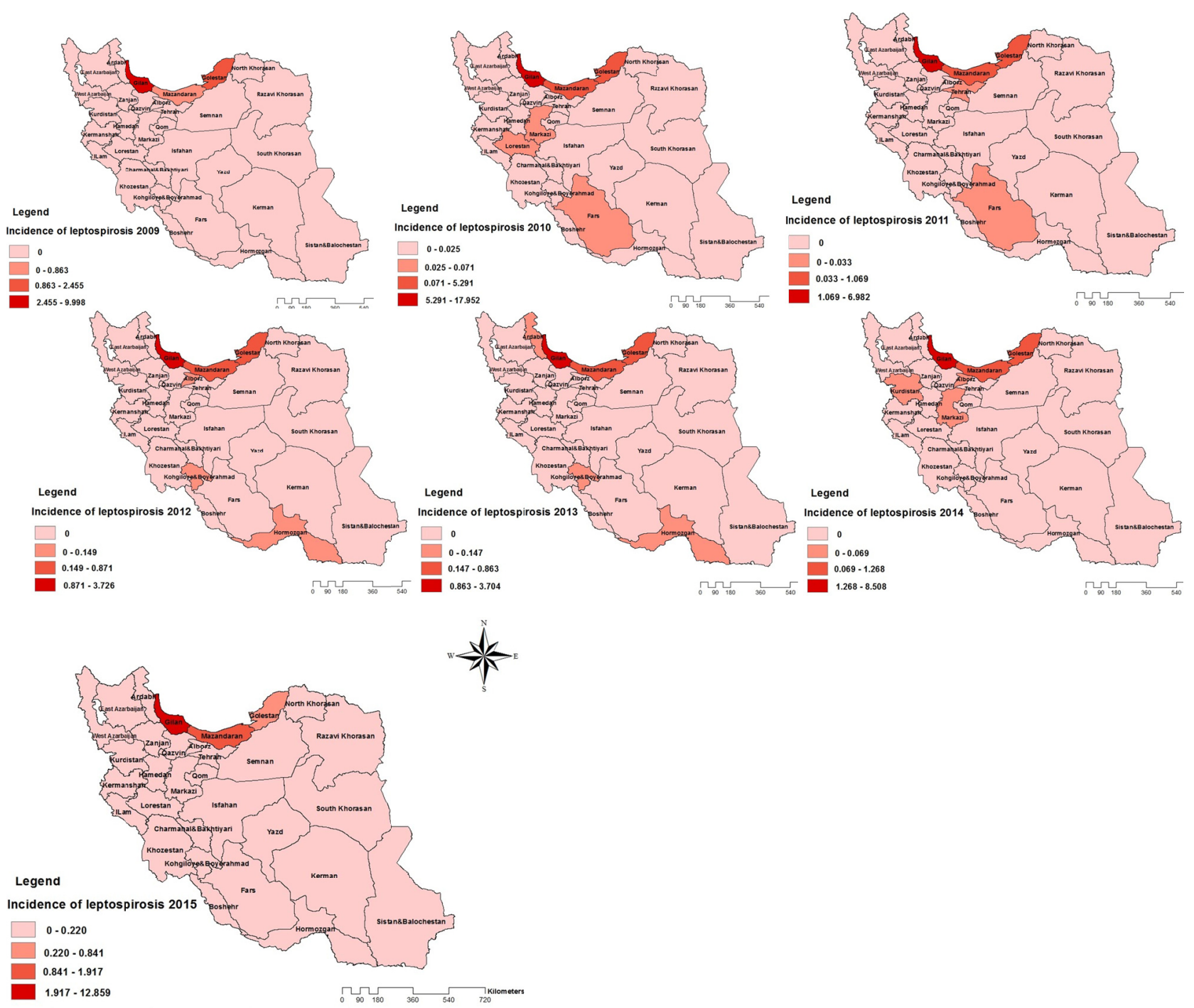

Fig. 3. Map of the incidence of leptospirosis disease in Iran from 2009-2015 


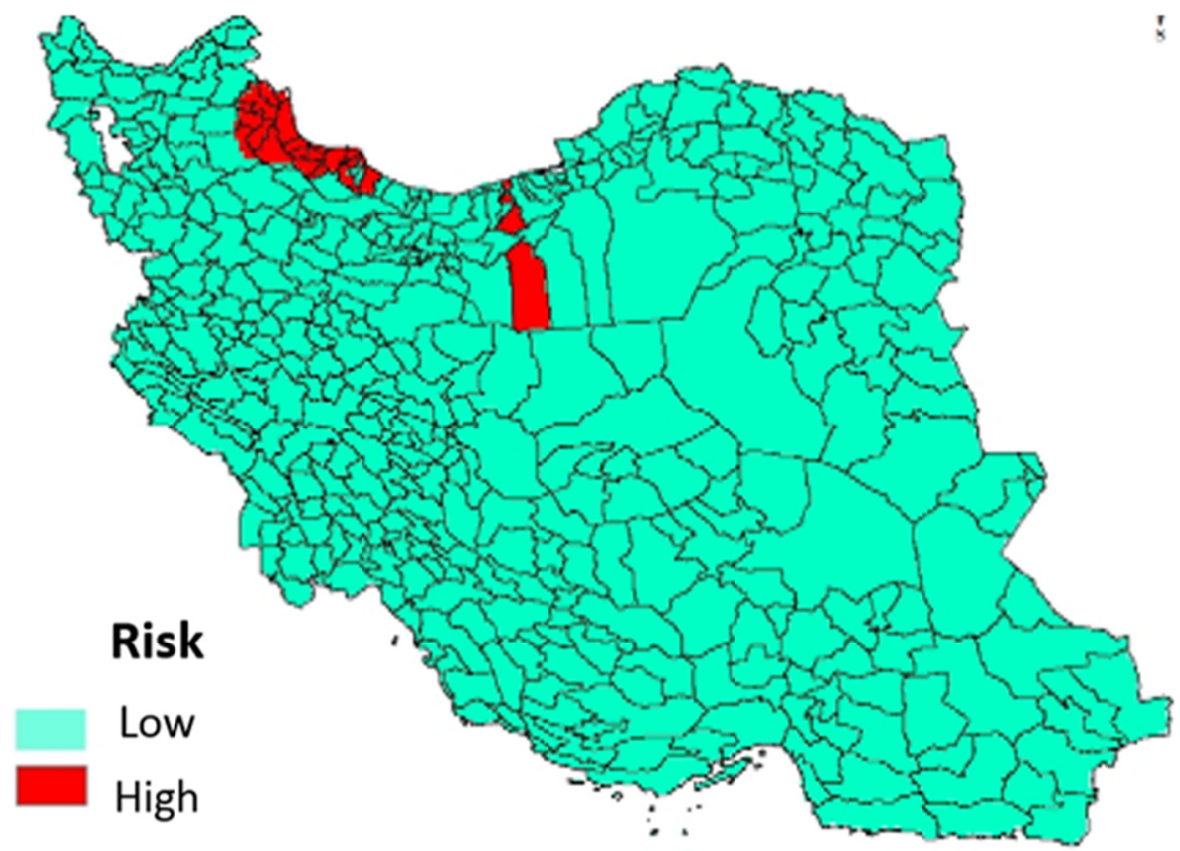

Fig. 4. Map of the region high risk of leptospirosis in Iran

Based on GIS maps throughout the country, of the total area of the country (14931 sq km²), 91\% includes parts of 6 provinces (Gilan, Mazandaran, Golestan, Zanjan, Ardebil, and Qazvin), which are at high risk of the incidence of leptospirosis in the coming years (2021). According to the results of the modeling in Iran, Gilan, Mazandaran, and Golestan provinces with $18.72 \%, 54.8 \%$, and $95.4 \%$ of their area $\left(\mathrm{km}^{2}\right)$, respectively, were the vulnerable areas at high risk of leptospirosis in Iran in the coming years (Fig. 4).

\section{Discussion}

The present study aimed at investigating the prevalence and incidence of leptospirosis and the prediction of highrisk areas in 2021 using the GIS. The GIS is a computerbased information system that records and evaluates geographical events occurring in the world. It can be of great help to researchers in understanding how disease spread and distribution are associated with the environmental factors (23).

In the present study, the geographical distribution of the disease over 6 years was determined through identifying spatial clusters and identifying high and low risk areas for leptospirosis. The results of our study showed that the prevalence and incidence of leptospirosis was higher in the northern provinces of Iran than in other regions from 2009 to 2015.

The highest estimates of disease incidence and mortality are related to North and Northeast Asia, Indian Subcontinent, Eastern Europe, Oceania, Caribbean, Andean, Central and Tropical Latin America, and East Sub-Saharan Africa. The incidence of the disease varies around the world, with about 10 to 975 patients per 100,000 population $(24,25)$.

In the present study, the highest incidence of the disease was reported in Astaneh Ashrafieh and Soumehsara towns in Gilan province (northern Iran), with 70 to 100 cases per 100,000 population in 2015 . In a study in 2 regions of Tanzania, the annual incidence of leptospirosis was reported to be 75 to 102 cases per 100,000 population (26).

On the other hand, the results of a systematic review study in Africa showed the high incidence of leptospirosis in island and dry areas (27). The majority of cases and deaths due to leptospirosis occur in tropical and lowincome countries (24), which is consistent with the results of the present study that showed the high prevalence of the disease in some areas of Semnan province, such as city of Sorkheh. Our results also showed that Golestan, Gilan, and Mazandaran provinces were the high-risk areas from 2009 to 2015. According to previous studies, the prevalence of leptospirosis is high in Gilan and Mazandaran $(28,29)$. Considering the distribution of leptospirosis in GIS maps, the cities of Rasht, Astaneh Ashrafieh, and Soumasara in Gilan province, respectively, had the highest prevalence and incidence in 2015.

The prevalence of the disease is influenced by environmental factors, such as temperate and warm climate, the rate of rainfall and humidity, the presence of surface and stable water, and the increase in rodent population (3033 ). Based on the results of the GIS analysis, the prevalence of leptospirosis has been high in Iran.

Numerous studies have shown that the prevalence of leptospirosis is high in the Caspian sea coastal area, as it has plain and humid climatic conditions $(3,34,35)$. This is consistent with the results of the present study. In Iran, the incidence of flooding and heavy rainfall is high in areas with a high incidence and prevalence of leptospirosis. As some studies have shown, after heavy rains or floods, an outbreak of leptospirosis occurs (36). In addition, according to a study conducted in Gilan, the annual average 
air temperature, rainfall, and humidity are directly associated with the number of cases of the disease (34).

On the other hand, the results of our study showed that the prevalence and incidence of leptospirosis in the provinces located in the Caspian coastal areas from 2009 to 2015 was much higher than that in other parts of the country, which could be due to the mild and humid climate of the region, abundance of surface waters, the presence of many rivers, the presence of domesticated livestock and rodents as the reservoirs of disease, working in paddy fields (the common job of the residents), or the lifestyle of the residents (3). Several studies in this field have found a significant relationship between living in rural areas and the incidence of infection due to different activities and lifestyles, as compared with families living in urban areas $(31,37-40)$. Leptospirosis is also an occupational disease that affects high-risk groups, such as sewage system workers, soldiers, and water sports athletes who are exposed to pathogenic factors, including animals or contaminated environments (40).

Many studies have confirmed that swimming in river water or walking without shoes on the lands contaminated with pathogens can cause leptospirosis (29). These findings are consistent with the results of our study, indicating that the prevalence and incidence of the disease is high in high-risk areas of Iran.

In this study, the Markov chain analysis was performed to determine geographical variations over 2 periods. Taking into consideration the plotted maps, the provinces of Golestan, Gilan, Mazandaran, and Semnan showed significant changes in the incidence rate in the specified location during the 2 periods. Accordingly, the incidence of the disease in these areas had been high for about 6 years, as compared with other areas.

The prevalence of leptospirosis has been increasing in recent years. Based on the CA-MARKOV modeling, the probability map of high-risk areas for leptospirosis in this study showed that a part of Semnan, Gilan, and Ardabil provinces in 2021 are among the high-risk areas for leptospirosis in Iran. It indicates the importance of paying attention to prevention programs.

It is worth mentioning that, when assessing diseases common to humans and animals (zoonotic diseases), it is of great importance to determine the main factors in disease control and prevention. Combining epidemiological approaches that determine disease-related factors with GIS methods, which determine the areas with these factors, can provide a method for studying the distribution of diseases affected by multiple environmental factors (23).

\section{Conclusion}

The prevalence of leptospirosis is influenced by geographical and climatic conditions of the region, and as indicated by the results of this study, the prevalence and incidence of the disease was high in the provinces located in the Caspian sea and some areas of Semnan province. It is also predicted that the incidence of prevalence of the disease remain high in these regions. Because of the environmental conditions favorable for the growth of the pathogens, high rates of occupational exposure, local residents' lifestyles, high rate of rainfall, and the incidence of flood, it is of great importance for health authorities to pay more attention to develop programs to prevent the spread of bacteria, identify the reservoirs of the disease, and train residents about the ways of the transmission of the disease.

\section{Acknowledgment}

This research is the result of a research project with ethics code IR.MUK.REC.1395.184 approved by Kurdistan University of Medical Sciences. The authors would like to express their thanks to the Center for Communicable Diseases Management, Ministry of Health and Medical Education, esteemed deputies of health affairs of medical sciences universities, responsible experts and the staff working in Communicable Diseases Prevention and Control Departments, experts and community health workers (Behvarzes) working in health centers and health houses across the country, as well as all people who helped us to perform this project.

\section{Conflict of Interests}

The authors declare that they have no competing interests.

\section{References}

1. Lau S, Low K, Khor K, Roslan M, Bejo S, Radzi R, et al. Prevalence of leptospirosis in healthy dogs and dogs with kidney disease in Klang Valley, Malaysia. Trop Biomed. 2016;33(3):469-75.

2. Abela-Ridder B, Sikkema R, Hartskeerl RA. Estimating the burden of human leptospirosis. Int J Antimicrob Agents. 2010;36:S5-S7.

3. Honarmand H, Mansour GF, Eshraghi S, Khoramizadeh MR. The epidemiology of leptospirosis in Guilan provice-2003. Gorgan Univ Med Sci. 2005;7(2):52-56.

4. Schneider MC JM, Buss DF, Aldighieri S, Bertherat E, Najera P, Galan DI, et al. Leptospirosis: a silent epidemic disease. Int J Environ Res Public Health. 2013;10(12):7229-34.

5. Esmaili R, Alhani F, Hesamzadeh A, Alizadeh Navaei R, Parsaei MR. A report of 102 patients with leptospirosis in Mazandaran province between 2003 and 2008. J Mazandaran Univ Med Sci. 2009;19(72):72-5.

6. Honarmand H, Eshraghy S, Khoramizadeh MR, Mansour GF, Falah M, Rezvani M, et al. Survey Spread of Positive Lepotospirosis by ELISA in Guilan Province. J Guilan Univ Med Sci. 2005;14(54):5965.

7. Honarmand H, Resaei H, Rezvani M, Hosseini S, Rahbar M. Ten years incidence of leptospirosis in guilan (1999 to 2008). Iran J Infect Dis Trop Med. 2010;14(47):47-53.

8. Brown P, McKenzie M, Pinnock M, McGrowder D. Environmental risk factors associated with leptospirosis among butchers and their associates in Jamaica. Int $\mathrm{J}$ Occup Environ Med (The IJOEM). 2011;2(1):223.

9. Arsang S, Kazemnejad A, Amani F. Epidemiology of tuberculosis in Iran (2001-08). J Gorgan Univ Med Sci. 2011;13(3):78-86.

10. Tanser F, Bärnighausen T, Cooke GS, Newell M-L. Localized spatial clustering of HIV infections in a widely disseminated rural South African epidemic. Int J Epidemiol. 2009;38(4):1008-16.

11. Zhi-Hang P, Yue-Jia C, Reilly KH, Lu W, Qian-Qian Q, Zheng-Wei $\mathrm{D}$, et al. Spatial distribution of HIV/AIDS in Yunnan province, People's Republic of China. Geospat Health. 2011;5(2):177-82.

12. Gatrell A, Senior M. Health and health care applications. Geographical information systems: Principles techniques management and applications. 1999; pp:258.

13. Boulos MK, Roudsari AV, Carson ER. Health geomatics: an enabling suite of technologies in health and healthcare. J Biomed Inform 2001;34(3):195-219.

14. Seif A, Rashidi M, Rozbahani R, Daheshti N, Poursafa P. GIS application in medical researches a solution for prevention from 
disease. J Esfahan Univ Med Sci. 2011;29(164):1-10.

15. Seif A, Rashidi M, Rozbahani R, Daheshti N, Poursafa PJ. GIS application in medical researches a solution for prevention from disease. Esfahan Univ Med Sci. 2011;29(164):1-10. [Persian].

16. Tanser FC, Le Sueur D. The application of geographical information systems to important public health problems in Africa. Int $\mathrm{J}$ Health Geogr. 2002;1(1):4.

17. Hassan A, Kenawy M, Kamal H, Abdel Sattar A, Sowilem M. GISbased prediction of malaria risk in Egypt. EMHJ 2003;9 (4):548-558,

18. Pordanjani SR, Atamaleki A, Amiri M, Khazaei Z, Fallahzadeh H, Alayi R, et al. Study on epidemiological status, spatial and temporal distribution of human brucellosis in kohgiluyeh and Boyer-Ahmad Province during 2011-2017. Adv Hum Biol. 2020;10(1):22.

19. Sipe NG, Dale P. Challenges in using geographic information systems (GIS) to understand and control malaria in Indonesia. Malar J. 2003;2(1):36.

20. Khoshdel A, Nouri Fard M, Pezeshkn R, Salahi Moghadam AR. Mapping of important diseases communicable in Iran. J health dev 2012;1(1):31-46.

21. Setianto A, Setianto A, Triandini T, Triandini T. Comparison of kriging and inverse distance weighted (IDW) interpolation methods in lineament extraction and analysis. J Sout Asia Appli Geol. 2013;5(1):21-9.

22. Getis A, Ord JK. The analysis of Spatial Association by use of Distance Statistics. Geographic Analysis. 1992;24(3):189-206.

23. Moore DA, Carpenter TE. Spatial analytical methods and geographic information systems: use in health research and epidemiology. Epidemiol Rev. 1999;21(2):143-61.

24. Costa F, Hagan JE, Calcagno J, Kane M, Torgerson P, MartinezSilveira MS, et al. Global morbidity and mortality of leptospirosis: a systematic review. Plos Negl Trop Dis. 2015;9(9):e0003898.

25. Pappas G, Papadimitriou P, Siozopoulou V, Christou L, Akritidis N. The globalization of leptospirosis: worldwide incidence trends. Int J Infect Dis. 2008;12(4):351-7.

26. Biggs HM, Hertz JT, Munishi OM, Galloway RL, Marks F, Saganda $\mathrm{W}$, et al. Estimating leptospirosis incidence using hospital-based surveillance and a population-based health care utilization survey in Tanzania. PloS Negl Trop Dis 2013;7(12):138.

27. Allan KJ, Biggs HM, Halliday JE, Kazwala RR, Maro VP, Cleaveland S, et al. Epidemiology of leptospirosis in Africa: a systematic review of a neglected zoonosis and a paradigm for 'One Health'in Africa. PLOS Negl Trop Dis. 2015;9(9):126.

28. Rahimi F, Vandyousefi J, Moradi BS, Bouzari M. Leptospirosis in the rural areas of Guilan province (2004-2005). J Kermanshah Univ Med Sci. 2007;2(33):197-205.

29. Esmaeili R, Hesamzadeh A, Alizadeh-Navaei R, Haghshenas M, Alhani F. Incidence of leptospirosis in Mazandaran Province, north of Iran: a one year survey. Pak J Biol Sci. 2009;12(19):1330.

30. Wiwanitkit V. A note from a survey of some knowledge aspects of leptospirosis among a sample of rural villagers in the highly endemic area, Thailand. Rural Remote Health . 2006;2(11):325.

31. Ashford DA, Kaiser RM, Spiegel RA, Perkins BA, Weyant RS, Bragg SL, et al. Asymptomatic infection and risk factors for leptospirosis in Nicaragua. Am J Trop Med Hyg. 2000;63(5):249-54.

32. Meslin F. Global aspects of emerging and potential zoonoses: a WHO perspective. Emerg Infect Dis. 1997;3(2):223.

33. Bharti AR, Nally JE, Ricaldi JN, Matthias MA, Diaz MM, Lovett MA, et al. Leptospirosis: a zoonotic disease of global importance. Lancet Infect Dis. 2003;3(12):757-71.

34. Mohammadinia A, Alimohammadi A, Habibi R. Assessment of environmental factors associated with rural endemics of Leptospirosis in Guilan Province, Iran. Sci Technol 2015;2(5):7.

35. Everard C, Edwards C, Everard J, Carrington D. A twelve-year study of leptospirosis on Barbados. Eur J Epidemiol. 1995;11(3):311-20..

36. Perrocheau A, Perolat P. Epidemiology of leptospirosis in New Caledonia (South Pacific): a one-year survey. Eur J Epidemiol. 1997; 13(2):161-7

37. Soori H, Hasani J, Entezami N, Hosseini S, Rafiei E. Assessment of Millennium Development Goals Indicators (MDGs) in Iran, Eastern Mediterranean Region, and the World: A Study Emerging from The MDGs Report 2014. Iran J Epidemiology. 2017;13(1):41-51.

38. Ciceroni L, Stepan E, Pinto A, Pizzocaro P, Dettori G, Franzin L, et al. Epidemiological trend of human leptospirosis in Italy between 1994 and 1996. Eur J Epidemiol. 2000;16(1):79-86.

39. Langston CE, Heuter KJ. Leptospirosis: A re-emerging zoonotic disease. Vet Clin North Am Small Anim. 2003;33(4):791-807.

40. Holk K, Nielsen SV, Rønne T. Human leptospirosis in Denmark 1970-1996: an epidemiological and clinical study. Scand J Infect Dis. 2000;32(5):533-8. 